\title{
Dominator Chromatic Number of Middle and Total Graphs
}

\author{
K. Kavitha \\ Research Scholar \\ Department of Mathematics, Madras Christian \\ College, Chennai - 600059
}

\author{
N.G. David \\ Associate Professor \\ Department of Mathematics, Madras Christian \\ College, Chennai - 600059
}

\begin{abstract}
Dominator chromatic number of middle and total graphs of various graph families is found in this paper. Also these parameters are compared with dominator chromatic number of their respective graph families.
\end{abstract}

Key words: Middle graph, total graph and dominator coloring.

AMS Subject Classification: 05C15, $05 \mathrm{C} 69$

\section{PRELIMINARIES}

The notion of middle graph, total graph and dominator coloring are reviewed in this section [1, 2, 3, 4].

\section{Definition 1.1}

The middle graph $\mathrm{M}(\mathrm{G})$ of a graph $\mathrm{G}$ is defined as follows. The vertex set of $M(G)$ is $V(G) \cup E(G)$. Two vertices $x, y$ in the vertex set of $M(G)$ are adjacent in $M(G)$ if either (i) $x, y$ are in $E(G)$ and $x, y$ are adjacent in $G$ or (ii) $x$ is in $V(G)$, $y$ is in $E(G)$ and $x, y$ are incident in $G$. In other words, $M(G)$ is obtained by subdividing each edge of $G$ exactly once and joining all these newly added middle vertices of adjacent edges of $\mathrm{G}$.

\section{Definition 1.2}

The total graph $\mathrm{T}(\mathrm{G})$ of a graph $\mathrm{G}$ is defined as a graph with vertex set $V(G) \cup E(G)$ and two vertices $x$, y of $T(G)$ are adjacent in $T(G)$ if either (i) $x, y$ are in $V(G)$ and $x$ is adjacent to $y$ in $\mathrm{G}$ or (ii) $\mathrm{x}, \mathrm{y}$ are in $\mathrm{E}(\mathrm{G})$ and $\mathrm{x}, \mathrm{y}$ are adjacent in $\mathrm{G}$ or (iii) $x$ is in $V(G)$, $y$ is in $E(G)$ and $x, y$ are incident in $G$.

\section{Definition 1.3}

A proper coloring of a graph $\mathrm{G}$ is an assignment of colors to the vertices of $\mathrm{G}$ in such a way that no two adjacent vertices receive the same color. The chromatic number $\chi(\mathrm{G})$, is the minimum number of colors required for a proper coloring of G. A Color class is the set of all vertices, having the same color. The color class corresponding to the color $\mathrm{i}$ is denoted by $\mathrm{V}_{\mathrm{i}}$.

\section{Definition 1.4}

A dominator coloring of a graph $\mathrm{G}$ is a proper coloring in which every vertex of $\mathrm{G}$ dominates every vertex of at least one color class. The convention is that if $\{\mathrm{v}\}$ is a color class, then $\mathrm{v}$ dominates the color class $\{\mathrm{v}\}$. The dominator chromatic number $\chi_{\mathrm{d}}(\mathrm{G})$ is the minimum number of colors required for a dominator coloring of $\mathrm{G}$.

\section{DOMINATOR CHROMATIC NUMBER OF MIDDLE GRAPHS}

Dominator chromatic number of middle graphs of various classes of graphs is obtained in this section.

\section{Theorem 2.1}

For cycle graph $\mathrm{C}_{\mathrm{n}}$ of order $\mathrm{n} \geq 3$, $\chi_{\mathrm{d}}\left[\mathrm{M}\left(\mathrm{C}_{\mathrm{n}}\right)\right]=[\mathrm{n} / 2+2$.

\section{Proof}

Let $C_{n}$ be the cycle graph of order $n \geq 3$ and let $V\left(C_{n}\right)=\left\{v_{1}\right.$, $\left.\mathrm{v}_{2}, \ldots, \mathrm{v}_{\mathrm{n}}\right\}$ and $\mathrm{E}\left(\mathrm{C}_{\mathrm{n}}\right)=\left\{\begin{array}{llll}\mathrm{e}_{1}, & \mathrm{e}_{2}, & \ldots, & \mathrm{e}_{\mathrm{n}}\end{array}\right.$, where $e_{i}=v_{i} v_{i+1}, 1 \leq i \leq n-1$ and $e_{n}=v_{n} v_{1}$. By the definition of middle graph, $\mathrm{M}\left(\mathrm{C}_{\mathrm{n}}\right)$ is obtained by subdividing each edge $\mathrm{v}_{\mathrm{i}} \mathrm{v}_{\mathrm{i}+1}, 1 \leq \mathrm{i} \leq \mathrm{n}-1$ of $\mathrm{C}_{\mathrm{n}}$ exactly once by the vertex $\mathrm{c}_{\mathrm{i}}$, and subdividing $\mathrm{v}_{\mathrm{n}} \mathrm{v}_{1}$ by $\mathrm{c}_{\mathrm{n}}$ in $\mathrm{M}\left(\mathrm{C}_{\mathrm{n}}\right)$ and joining $\left(\mathrm{c}_{\mathrm{i}}\right.$ and $\left.\mathrm{c}_{\mathrm{i}+1}\right)$, $1 \leq \mathrm{i} \leq \mathrm{n}-1$ and $\left(\mathrm{c}_{\mathrm{n}}\right.$ and $\left.\mathrm{c}_{1}\right)$. Let $\mathrm{V}_{1}=\left\{\mathrm{v}_{1}, \mathrm{v}_{2}, \ldots, \mathrm{v}_{\mathrm{n}}\right\}$ and $\mathrm{V}_{2}=\left\{\mathrm{c}_{1}, \mathrm{c}_{2}, \ldots, \mathrm{c}_{\mathrm{n}}\right\}$. Then $\mathrm{V}\left(\mathrm{M}\left(\mathrm{C}_{\mathrm{n}}\right)\right)=\mathrm{V}_{1} \cup \mathrm{V}_{2}$.

The following procedure gives a dominator coloring of $\mathrm{M}\left(\mathrm{C}_{\mathrm{n}}\right)$. Color the vertices $\mathrm{v}_{\mathrm{i},}, 1 \leq \mathrm{i} \leq \mathrm{n}$ by color 1 . When $\mathrm{n}$ is odd, $\mathrm{c}_{2}, \mathrm{c}_{4}, \mathrm{c}_{6}, \ldots, \mathrm{c}_{\mathrm{n}-3}$ and $\mathrm{c}_{\mathrm{n}}$ are colored by color 2 and $\mathrm{c}_{1}, \mathrm{c}_{3}$, $\mathrm{c}_{5}, \ldots, \mathrm{c}_{\mathrm{n}-2}$ and $\mathrm{c}_{\mathrm{n}-1}$ by colors $3,4,5, \ldots,\lceil\mathrm{n} / 2\rceil+2$. When $\mathrm{n}$ is even, $c_{2}, c_{4}, c_{6}, \ldots, c_{n}$ are colored by color 2 and $c_{1}, c_{3}, c_{5}, \ldots$, $\mathrm{c}_{\mathrm{n}-1}$ by colors $3,4,5, \ldots,\lceil\mathrm{n} / 2\rceil+2$.

The vertices $v_{i}$ and $v_{i+1}$ dominate the color class of $c_{i}, i=1,3$, $5, \ldots$ The center vertices $c_{1}, c_{3}, c_{5}, \ldots$ dominate themselves and $c_{2}$ and $c_{n}$ dominate the color class 3 , as they are adjacent to $c_{1}$. The vertex $c_{2 i}, \mathrm{i}=2,3, \ldots, \mid n / 2$ dominates the color class of $c_{2 i+1}$. Hence $\chi_{\mathrm{d}}\left[\mathrm{M}\left(\mathrm{C}_{\mathrm{n}}\right)\right]=\left\lceil\mathrm{n} / 2^{-}+2\right.$.

The following example illustrates the procedure discussed in the above result.

\section{Example 2.2}

In figure 1 , middle graph of $\mathrm{C}_{6}$ is depicted with a dominator coloring. 


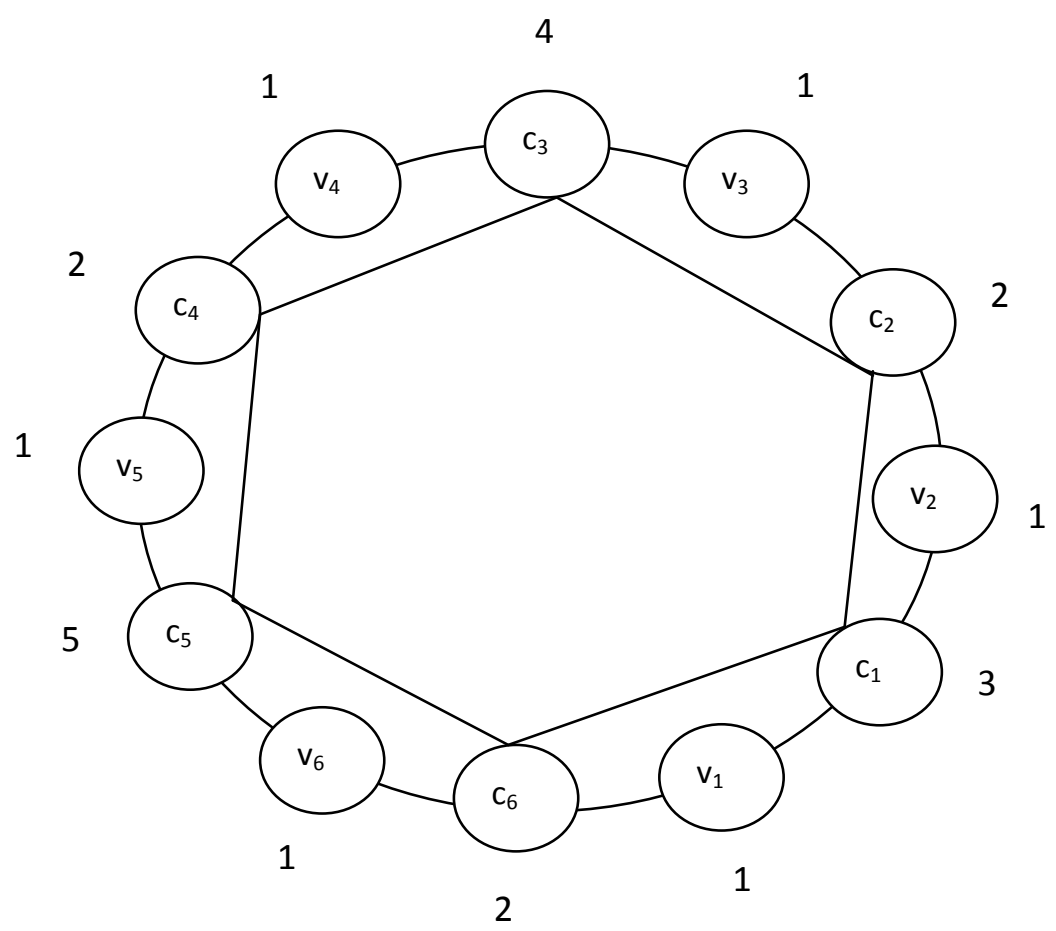

Figure 1

The color classes of $\mathrm{M}\left(\mathrm{C}_{6}\right)$ are $\mathrm{V}_{1}=\left\{\mathrm{v}_{1}, \mathrm{v}_{2}, \mathrm{v}_{3}, \mathrm{v}_{4}, \mathrm{v}_{5}, \mathrm{v}_{6}\right\}, \mathrm{V}_{2}=\left\{\mathrm{c}_{2}, \mathrm{c}_{4}, \mathrm{c}_{6}\right\}, \mathrm{V}_{3}=\left\{\mathrm{c}_{1}\right\}, \mathrm{V}_{4}=\left\{\mathrm{c}_{3}\right\}$ and $\mathrm{V}_{5}=\left\{\mathrm{c}_{5}\right\}$. The dominator chromatic number is, $\chi_{\mathrm{d}}\left[\mathrm{M}\left(\mathrm{C}_{6}\right)\right]=5$.

\section{Theorem 2.3}

For path graph $\mathrm{P}_{\mathrm{n}}$ of order $\mathrm{n} \geq 2$,

$\chi_{d}\left[M\left(P_{n}\right)\right]=\left\{\begin{array}{cc}n & \text { when } n=3,4 \\ 2+\sqrt{n} / 2 & \text { otherwise. }\end{array}\right.$

\section{Proof}

Let $P_{n}$ be a path of order $n \geq 2$ with vertex labels $v_{1}, v_{2}, \ldots, v_{n}$. By the definition of middle graph, $\mathrm{M}\left(\mathrm{P}_{\mathrm{n}}\right)$ has the vertex set $\mathrm{V}\left(\mathrm{P}_{\mathrm{n}}\right) \cup \mathrm{E}\left(\mathrm{P}_{\mathrm{n}}\right)=\left\{\mathrm{v}_{\mathrm{i}} / 1 \leq \mathrm{i} \leq \mathrm{n}\right\} \cup\left\{\mathrm{e}_{\mathrm{i}} / 1 \leq \mathrm{i} \leq \mathrm{n}-1\right\}$ in which each $e_{i}$ is adjacent to $v_{i}$ and $v_{i+1}, 1 \leq \mathrm{i} \leq \mathrm{n}-1$ and also adjacent to $\mathrm{e}_{\mathrm{i}+1}$, for $1 \leq \mathrm{i} \leq \mathrm{n}-2$.

A dominator coloring of $\mathrm{M}\left(\mathrm{P}_{\mathrm{n}}\right)$ is obtained by coloring the vertices $\mathrm{v}_{\mathrm{i}}, 1 \leq \mathrm{i} \leq \mathrm{n}$ by color 1 , even subscripted middle vertices $c_{2}, c_{4}, \ldots$, by color 2 and the remaining odd subscripted middle vertices $c_{1}, c_{3}, c_{5}, \ldots$ are colored respectively by colors $3,4,5, \ldots,\lceil\mathrm{n} / 2\rceil+2$.

The odd subscripted middle vertices $c_{1}, c_{3}, c_{5}, \ldots$ dominate themselves and the vertices $v_{i}$ and $v_{i+1}$ dominate the color class of $c_{i}, i=1,3,5, \ldots$. The vertex $c_{i}$ dominates the color class of $\mathrm{c}_{\mathrm{i}+1}, \mathrm{i}=2,4, \quad \ldots$ Hence $\chi_{d}\left[M\left(P_{n}\right)\right]=\left\{\begin{array}{cc}n & \text { when } n=3,4 \\ 2+\sqrt{n} / 2 & \text { otherwise. }\end{array}\right.$

\section{Theorem 2.4}

For wheel graph $\mathrm{W}_{1, \mathrm{n}}$ of order $\mathrm{n} \geq 3$, $\chi_{\mathrm{d}}\left[\mathrm{M}\left(\mathrm{W}_{1, \mathrm{n}}\right)\right]=\mathrm{n}+2$.

\section{Proof}

Let $\mathrm{W}_{1, \mathrm{n}}$ be a wheel graph of order $\mathrm{n} \geq 3$. Let the vertex at the centre be $\mathrm{v}_{1}$ and the vertices on the rim be $\mathrm{v}_{2}, \mathrm{v}_{3}, \ldots, \mathrm{v}_{\mathrm{n}+1}$. By the definition of middle graph, we subdivide each edge exactly once and join all the middle vertices of adjacent edges of $\mathrm{W}_{1, \mathrm{n}}$. Let the middle vertices on the edges $\mathrm{v}_{1} \mathrm{v}_{\mathrm{i}}, \mathrm{i}=2, \ldots, \mathrm{n}+1$ of $\mathrm{W}_{1, \mathrm{n}}$ be $\mathrm{c}_{\mathrm{i}-1}$ and the middle vertices on $v_{i} v_{i+1}, i=2, \ldots, n$ of $W_{1, n}$ be $c_{n+i-1}$ and the middle vertex on $v_{n+1} v_{2}$ be $c_{2 n}$

A dominator coloring of $\mathrm{M}\left(\mathrm{W}_{1, \mathrm{n}}\right)$ is obtained by the following procedure. Color the vertex $\mathrm{v}_{1}$ by color 1 and assign colors 2 , $3, \ldots, n+1$ for the induced clique $c_{1}, c_{2}, \ldots, c_{n}$. Color the vertices $v_{2}, v_{3}$ and $c_{n+1}$ by colors 3,2 and $(n+2)$ respectively. The remaining $2 \mathrm{n}-3$ vertices on the rim of $\mathrm{M}\left(\mathrm{W}_{1, n}\right)$ are colored by using colors 1,2 and 3 in a particular fashion.

The vertices $c_{3}, c_{4}, \ldots, c_{n}$ and $c_{n+1}$ dominate themselves. The vertices $c_{1}, c_{2}, v_{2}$ and $v_{3}$ dominate the color class $(n+2)$, as they are adjacent to the vertex $c_{n+1}$. The remaining $2 n-3$ vertices $\mathrm{v}_{4}, \mathrm{c}_{\mathrm{n}+3}, \mathrm{v}_{5}, \mathrm{c}_{\mathrm{n}+4}, \ldots, \mathrm{c}_{2 \mathrm{n}}$ and $\mathrm{v}_{\mathrm{n}}$ on the rim of $\mathrm{M}\left(\mathrm{W}_{1, \mathrm{n}}\right)$ dominate respective color classes from 4 to $(n+1)$. The vertex $\mathrm{v}_{1}$ dominates all color classes between 4 and $(\mathrm{n}+1)$. Hence $\chi_{\mathrm{d}}\left[\mathrm{M}\left(\mathrm{W}_{1, \mathrm{n}}\right)\right]=\mathrm{n}+2$. 


\section{Example 2.5}

In figure 2, middle graph of $\mathrm{W}_{1,5}$ is depicted with a dominator coloring.

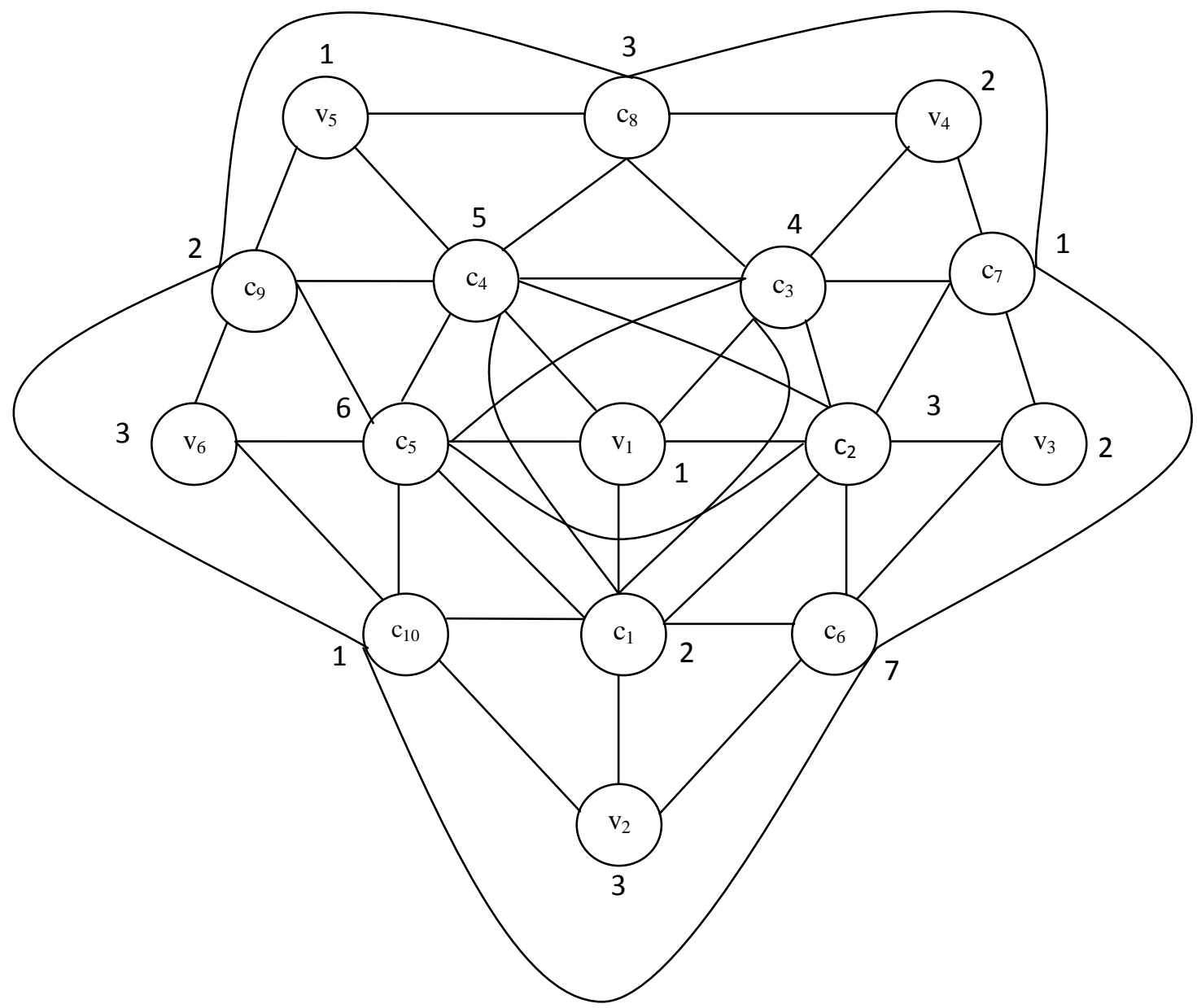

Figure 2

The color classes of $\mathrm{M}\left(\mathrm{W}_{1,5}\right)$ are $\mathrm{V}_{1}=\left\{\mathrm{v}_{1}, \mathrm{c}_{7}, \mathrm{v}_{5}, \mathrm{c}_{10}\right\}, \mathrm{V}_{2}=\left\{\mathrm{c}_{1}, \mathrm{v}_{3}, \mathrm{v}_{4}, \mathrm{c}_{9}\right\}, \mathrm{V}_{3}=\left\{\mathrm{c}_{2}, \mathrm{v}_{2}, \mathrm{c}_{8}, \mathrm{v}_{6}\right\}, \mathrm{V}_{4}=\left\{\mathrm{c}_{3}\right\}, \mathrm{V}_{5}=\left\{\mathrm{c}_{4}\right\}$, $\mathrm{V}_{6}=\left\{\mathrm{c}_{5}\right\}$ and $\mathrm{V}_{7}=\left\{\mathrm{c}_{6}\right\}$. The dominator chromatic number is, $\chi_{\mathrm{d}}\left[\mathrm{M}\left(\mathrm{W}_{1,5}\right)\right]=7$.

\section{DOMINATOR CHROMATIC} NUMBER OF TOTAL GRAPHS

In this section, dominator chromatic number of total graphs of various classes of graphs is obtained

\section{Theorem 3.1}

For cycle graph $\mathrm{C}_{\mathrm{n}}$ of order $\mathrm{n} \geq 3$, $\chi_{d}\left[T\left(C_{n}\right)\right]= \begin{cases}2+\sqrt{2} \mathrm{n} / 5^{-} & \text {when } \mathrm{n}=3 \\ 3+\sqrt{2} \mathrm{n} / 5 & \text { otherwise. }\end{cases}$

\section{Proof}

Let $C_{n}$ be the cycle graph of order $n \geq 3$ and let $V\left(C_{n}\right)=\left\{v_{1}\right.$,

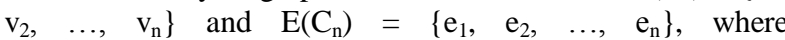
$e_{i}=v_{i} v_{i+1}, 1 \leq i \leq n-1$ and $e_{n}=v_{n} v_{1}$. By the definition of total graph, $T\left(C_{n}\right)$ can be obtained by subdividing each edge $v_{i} v_{i+1}$, $1 \leq \mathrm{i} \leq \mathrm{n}-1$ of $\mathrm{C}_{\mathrm{n}}$ exactly once in $\mathrm{T}\left(\mathrm{C}_{\mathrm{n}}\right)$ and joining all these middle vertices of adjacent edges of $C_{n}$ and also joining the adjacent vertices of $C_{n}$. Let the vertices of $T\left(C_{n}\right)$ be labeled by $\mathrm{u}_{1=} \mathrm{v}_{1}, \mathrm{u}_{2}, \mathrm{u}_{3}, \ldots, \mathrm{u}_{2 \mathrm{n}}$.

A dominator coloring of $T\left(C_{n}\right), n \geq 4$ is obtained by the following procedure. The vertex $\mathrm{u}_{1+5 \mathrm{j}}$ is colored by $4+\mathrm{j}$, $0 \leq \mathrm{j} \leq \coprod(2 \mathrm{n}-1) / 5$. The vertices $\mathrm{u}_{2+5 \mathrm{j}}, \mathrm{u}_{3+5 \mathrm{j}}, \mathrm{u}_{4+5 \mathrm{j}}, \mathrm{u}_{5+5 \mathrm{j}}$,

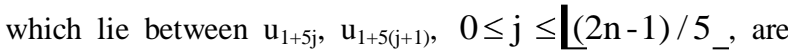


colored by $(1,2,3,1)$ or $(2,3,1,2)$ depending on whether $\mathrm{j}$ is even or odd.

Vertex $\mathrm{u}_{1+5 \mathrm{j}}$ dominates itself and $\mathrm{u}_{1+5 \mathrm{j}-2}, \mathrm{u}_{1+5 \mathrm{j}-1}, \mathrm{u}_{1+5 \mathrm{j}+1}, \mathrm{u}_{1+5 \mathrm{j}+2}$ dominate the color class $(4+\mathrm{j})$, as they are adjacent to $\mathrm{u}_{1+5 \mathrm{j}}$, $0<\mathrm{j} \leq\left\lfloor(2 \mathrm{n}-1) / 5_{-} \quad\right.$ and when $\mathrm{j}=0$, $\mathrm{u}_{2}, \mathrm{u}_{3}, \mathrm{u}_{2 \mathrm{n}}, \mathrm{u}_{2 \mathrm{n}-1}$ dominate the color class 4 . When $\mathrm{n}=3$, it is easy to see that $\chi_{\mathrm{d}}\left[\mathrm{T}\left(\mathrm{C}_{3}\right)\right]=2+[2 \mathrm{n} / 5$. Hence

$\chi_{d}\left[T\left(C_{n}\right)\right]= \begin{cases}2+\sqrt{2} \mathrm{n} / 5^{-} & \text {when } \mathrm{n}=3 \\ 3+\sqrt{2} \mathrm{n} / 5^{-} & \text {otherwise. }\end{cases}$

\section{Theorem 3.2}

For path graph $\mathrm{P}_{\mathrm{n}}$ of order $\mathrm{n} \geq 3$, $\chi_{\mathrm{d}}\left[\mathrm{T}\left(\mathrm{P}_{\mathrm{n}}\right)\right]= \begin{cases}{\left[2 \mathrm{n} / 3^{-}+2\right.} & \text { when } \mathrm{n}=3 \\ {\left[2 \mathrm{n} / 3^{-}+1\right.} & \text { otherwise. }\end{cases}$

\section{Proof}

Let $P_{n}$ be a path of order $n \geq 3$ with vertex labels $\mathrm{v}_{1}, \mathrm{v}_{2}, \ldots, \mathrm{v}_{\mathrm{n}}$. By the definition of total graph, $\mathrm{T}\left(\mathrm{P}_{\mathrm{n}}\right)$ can be obtained by subdividing each edge of $P_{n}$ exactly once in $T\left(P_{n}\right)$ and joining all these middle vertices of adjacent edges of $P_{n}$ and also joining the adjacent vertices of $P_{n}$. The vertex set of $\mathrm{T}\left(\mathrm{P}_{\mathrm{n}}\right)$ is $\mathrm{V}\left(\mathrm{P}_{\mathrm{n}}\right) \cup \mathrm{E}\left(\mathrm{P}_{\mathrm{n}}\right)=\left\{\mathrm{v}_{\mathrm{i}} / 1 \leq \mathrm{i} \leq \mathrm{n}\right\} \cup\left\{\mathrm{e}_{\mathrm{i}} / 1 \leq \mathrm{i} \leq \mathrm{n}-1\right\}$. Relabel the vertices of $T\left(P_{n}\right)$ by $u_{1}=v_{1}, u_{2}=c_{1}, u_{3}=v_{2}, \ldots, u_{2 n}$. ${ }_{1}$ consecutively.

A dominator coloring of $\mathrm{T}\left(\mathrm{P}_{\mathrm{n}}\right), \mathrm{n} \geq 4$ is obtained by coloring the vertex $\mathrm{u}_{1+3 \mathrm{i}}$ by color $1, \mathrm{u}_{2+3 \mathrm{i}}$ by color 2 and $\mathrm{u}_{3+3 \mathrm{i}}$ by color $(3+\mathrm{i}), 0 \leq \mathrm{i} \leq 1+\sqrt{2} \mathrm{n} / 3$. Vertex $\mathrm{u}_{3+3 \mathrm{i}}$ dominates itself and $\mathrm{u}_{3+3 \mathrm{i}-2}, \mathrm{u}_{3+3 \mathrm{i}-1}, \mathrm{u}_{3+3 \mathrm{i}+1}, \mathrm{u}_{3+3 \mathrm{i}+2}$ dominate the color class $(3+\mathrm{i})$, as they are adjacent to $\mathrm{u}_{3+3 \mathrm{i}}, 0 \leq \mathrm{i} \leq 1+\sqrt{2} \mathrm{n} / 3$. When $\mathrm{n}=3$, it is easy to see that $\chi_{\mathrm{d}}\left[\mathrm{T}\left(\mathrm{P}_{3}\right)\right]=[2 \mathrm{n} / 3-2$. Hence $\chi_{d}\left[T\left(P_{n}\right)\right]= \begin{cases}{\left[2 n / 3^{-}+2\right.} & \text { when } n=3 \\ 2 n / 3^{-}+1 & \text { otherwise. }\end{cases}$

The following example illustrates the procedure discussed in the above result.

\section{Example 3.3}

In figure 3 , total graph of $\mathrm{P}_{5}$ is depicted with a dominator coloring.

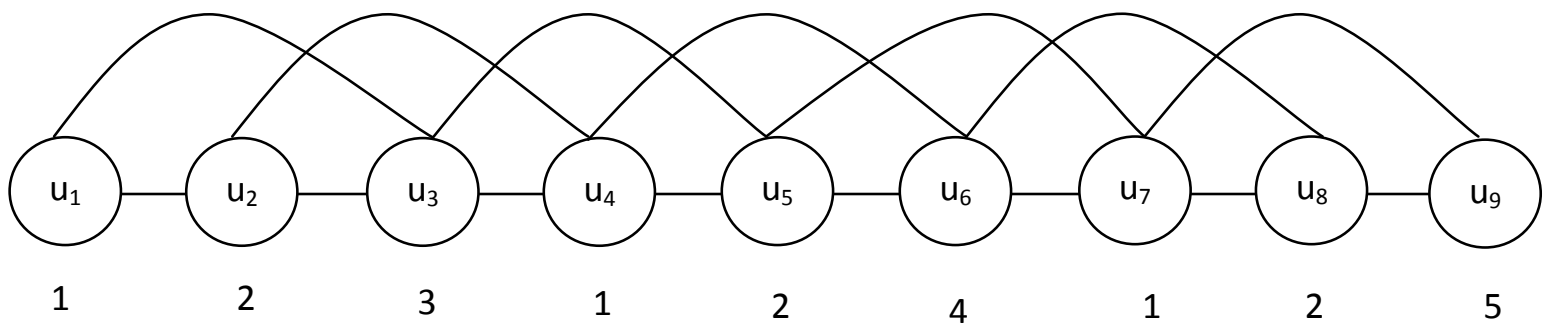

Figure 3

The color classes of $\mathrm{T}\left(\mathrm{P}_{5}\right)$ are $\mathrm{V}_{1}=\left\{\mathrm{u}_{1}, \mathrm{u}_{4}, \mathrm{u}_{7}\right\}, \mathrm{V}_{2}=\left\{\mathrm{u}_{2}, \mathrm{u}_{5}, \mathrm{u}_{8}\right\}, \mathrm{V}_{3}=\left\{\mathrm{u}_{3}\right\}, \mathrm{V}_{4}=\left\{\mathrm{u}_{6}\right\}$ and $\mathrm{V}_{5}=\left\{\mathrm{u}_{9}\right\}$. The dominator chromatic number is, $\chi_{\mathrm{d}}\left[\mathrm{T}\left(\mathrm{P}_{5}\right)\right]=5$.

\section{Theorem 3.4}

For wheel graph $\mathrm{W}_{1, \mathrm{n}}$ of order $\mathrm{n} \geq 3$, $\chi_{\mathrm{d}}\left[\mathrm{T}\left(\mathrm{W}_{1, \mathrm{n}}\right)\right]=\mathrm{n}+2$.

\section{Proof}

Let $\mathrm{W}_{1, \mathrm{n}}$ be a wheel graph of order $\mathrm{n} \geq 3$. Let the vertices of the wheel graph be labeled as follows. The vertex at the centre is labeled by $\mathrm{v}_{1}$ and the vertices on the rim be labeled consecutively by $\mathrm{v}_{2}, \mathrm{v}_{3}, \ldots, \mathrm{v}_{\mathrm{n}+1}$. By the definition of total graph, we subdivide each edge exactly once and join all the middle vertices of adjacent edges and join all the adjacent vertices of $W_{1, n}$. Let the middle vertices on the edges $v_{1} v_{i}$, $\mathrm{i}=2, \ldots, \mathrm{n}+1$ of $\mathrm{W}_{1, \mathrm{n}}$ be $\mathrm{c}_{\mathrm{i}-1}$ and the middle vertices on $\mathrm{v}_{\mathrm{i}} \mathrm{v}_{\mathrm{i}+1}$, $\mathrm{i}=2, \ldots, \mathrm{n}$ of $\mathrm{W}_{1, \mathrm{n}}$ be $\mathrm{c}_{\mathrm{n}+\mathrm{i}-1}$ and the middle vertex on $\mathrm{v}_{\mathrm{n}+1} \mathrm{v}_{2}$ is $c_{2 n}$.
The coloring of $\mathrm{T}\left(\mathrm{W}_{1, n}\right)$ can be done in a similar way as described in theorem 2.4. Domination of vertices can also be argued in the same manner. Hence $\chi_{\mathrm{d}}\left[\mathrm{T}\left(\mathrm{W}_{1, \mathrm{n}}\right)\right]=\mathrm{n}+2$.

By combining the observations of [2] and the theorems proved above, we have the following result.

\section{Result 3.5}

(i) $\quad \chi_{d}\left[M\left(C_{n}\right)\right]>\chi_{d}\left(C_{n}\right)$ and $\chi_{d}\left[T\left(C_{n}\right)\right]>\chi_{d}\left(C_{n}\right)$

(ii) $\quad \chi_{d}\left[\mathrm{M}\left(\mathrm{P}_{\mathrm{n}}\right)\right]>\chi_{\mathrm{d}}\left(\mathrm{P}_{\mathrm{n}}\right)$ and $\chi_{\mathrm{d}}\left[\mathrm{T}\left(\mathrm{P}_{\mathrm{n}}\right)\right]>\chi_{\mathrm{d}}\left(\mathrm{P}_{\mathrm{n}}\right)$

(iii) $\quad \chi_{\mathrm{d}}\left[\mathrm{M}\left(\mathrm{W}_{1, \mathrm{n}}\right)\right]>\chi_{\mathrm{d}}\left(\mathrm{W}_{1, \mathrm{n}}\right)$ and $\chi_{\mathrm{d}}\left[\mathrm{T}\left(\mathrm{W}_{1, \mathrm{n}}\right)\right]>\chi_{\mathrm{d}}\left(\mathrm{W}_{1, \mathrm{n}}\right)$. 


\section{CONCLUSION}

In this paper, we obtained the dominator chromatic number of middle and total graphs and compared these parameters with dominator chromatic number of the corresponding graph families. This paper can further be extended by identifying graph families of graphs for which this chromatic number is equal to other kinds of chromatic number.

\section{ACKNOWLEDGMENTS}

The authors wish to thank the referee and the Editor-in-Chief for their encouragements and helpful suggestions and comments to improve this paper.

\section{REFERENCES}

[1] J. A. Bondy and U.S.R. Murty, Graph theory with Applications, London: MacMillan (1976).

[2] R.M. Gera, On Dominator Colorings in Graphs, Graph Theory Notes of New York LIT, 25-30 (2007)

[3] F. Harary, Graph Theory, Narosa Publishing 1969.

[4] D. Michalak, On Middle and Total graphs with Coarseness Number Equal 1, Lecture Notes in Mathematics, Volume 1018: Graph Theory, SpringerVerlag, Berlin, 139 - 150 (1983). 